\title{
Attenuation of ocean surface waves in pancake and frazil sea ice along the coast of the Chukchi Sea
}

Article

Published Version

Creative Commons: Attribution-Noncommercial 4.0

Open access

Hosekova, L. ORCID: https://orcid.org/0000-0003-0242-7078, Malila, M. P. ORCID: https://orcid.org/0000-0002-2731-0901, Rogers, W. E. ORCID: https://orcid.org/0000-0001-8235-2218, Roach, L. A. ORCID: https://orcid.org/0000-0003-4189-3928, Eidam, E. ORCID: https://orcid.org/0000-0002-1906-8692, Rainville, L. ORCID: https://orcid.org/0000-0001-7337-225X, Kumar, N. ORCID: https://orcid.org/0000-0002-7972-2756 and Thomson, J. ORCID: https://orcid.org/0000-0002-8929-0088 (2020) Attenuation of ocean surface waves in pancake and frazil sea ice along the coast of the Chukchi Sea. Journal of Geophysical Research: Oceans, 125 (12). e2020JC016746. ISSN 2169-9291 doi: https://doi.org/10.1029/2020JC016746 Available at https://centaur.reading.ac.uk/95006/

It is advisable to refer to the publisher's version if you intend to cite from the work. See Guidance on citing.

To link to this article DOI: http://dx.doi.org/10.1029/2020JC016746

Publisher: American Geophysical Union 
All outputs in CentAUR are protected by Intellectual Property Rights law, including copyright law. Copyright and IPR is retained by the creators or other copyright holders. Terms and conditions for use of this material are defined in the End User Agreement.

\section{www.reading.ac.uk/centaur}

\section{CentAUR}

Central Archive at the University of Reading

Reading's research outputs online 


\section{JGR Oceans}

\author{
RESEARCH ARTICLE \\ 10.1029/2020JC016746 \\ $\dagger$ Deceased \\ Key Points: \\ - Buoy observations are used to \\ calculate spectral attenuation rates \\ of surface waves in pancake and \\ frazil sea ice near the coast of Alaska \\ - Consistently higher attenuation \\ is observed near the ice edge than \\ further in the ice cover \\ - Attenuation rates follow a power- \\ law dependence on frequency and \\ are applicable to parametrization \\ schemes in wave forecast models
}

Correspondence to:

L. Hošeková,

lhosek@uw.edu

\section{Citation:}

Hošeková, L., Malila, M. P., Rogers, W. E., Roach, L. A., Eidam, E., Rainville, L., et al. (2020). Attenuation of ocean surface waves in pancake and frazil sea ice along the coast of the Chukchi Sea. Journal of Geophysical Research: Oceans, 125, e2020JC016746. https:// doi.org/10.1029/2020JC016746

Received 27 AUG 2020 Accepted 18 NOV 2020

\section{Attenuation of Ocean Surface Waves in Pancake and Frazil Sea Ice Along the Coast of the Chukchi Sea}

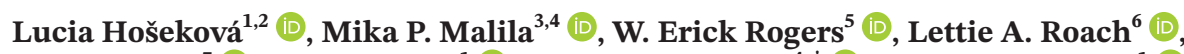

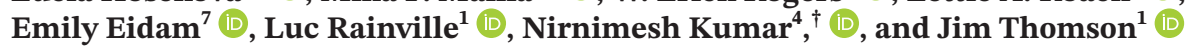

${ }^{1}$ Applied Physics Laboratory, University of Washington, Seattle, WA, USA, ${ }^{2}$ Department of Meteorology, University of Reading, Reading, UK, ${ }^{3}$ Norwegian Meteorological Institute, Bergen, Norway, ${ }^{4}$ Department of Civil and Environmental Engineering, University of Washington, Seattle, USA, ${ }^{5}$ Naval Research Laboratory, Stennis Space Center, MS, USA, ${ }^{6}$ Department of Atmospheric Sciences, University of Washington, Seattle, WA, USA, ${ }^{7}$ Department of Marine Sciences, University of North Carolina, Chapel Hill, NC, USA

\begin{abstract}
Alaskan Arctic coastlines are protected seasonally from ocean waves by the presence of coastal and shorefast sea ice. This study presents field observations collected during the autumn 2019 freeze up near Icy Cape, a coastal headland in the Chukchi Sea of the Western Arctic. The evolution of the coupled air-ice-ocean-wave system during a 4-day wave event was monitored using drifting wave buoys, a cross-shore mooring array, and ship-based measurements. The incident wavefield with peak period of $2.5 \mathrm{~s}$ was attenuated by coastal pancake and frazil sea ice, reducing significant wave height by $40 \%$ over less than $5 \mathrm{~km}$ of cross-shelf distance spanning water depths from 13 to $30 \mathrm{~m}$. Spectral attenuation coefficients are evaluated with respect to wave and ice conditions and the proximity to the ice edge. Attenuation rates are found to be three times higher within $500 \mathrm{~m}$ of the ice edge, relative to values farther in the ice cover. Attenuation coefficients are in the range of $\langle 2.3,2.7\rangle \times 10^{-3} \mathrm{~m}^{-1}$, and follow a power-law dependence on frequency.
\end{abstract}

Plain Language Summary Changes in Arctic sea ice cover have consequences for coastal Alaskan regions. Relative to recent decades, nearshore sea ice now melts earlier and forms later in the year, exposing the coastlines to increased ocean wave energy and storm surges. Recent reports show that erosion along Arctic coasts is increasing and poses a threat to local habitats and human communities. This study aims to improve our understanding of the protective role of sea ice by measuring wave energy across the nearshore ice cover. Using drifting buoys deployed inside and outside fragmented sea ice, we monitored ocean waves during an autumn storm event typical for coastal regions in the Chukchi Sea. We found that the wave heights were reduced by $40 \%$ over $5 \mathrm{~km}$ distance, and the effects of this type of ice on waves were consistent with previous studies. Thanks to the high resolution of our measurements, we were able to determine that the dampening effect was stronger immediately next to the ice edge. Our measurements may be applied to improve present and future operational and climate models used to forecast and understand wave activity near the Arctic coasts.

\section{Introduction}

The Arctic region is a rapidly changing environment, characterized by increasing rates of summer sea ice decline, rising temperatures, and lengthening open-water seasons. Arctic coastlines are considered particularly vulnerable to these changing conditions, which pose a unique threat to biological systems, human communities, and infrastructure (Forbes, 2011). Indeed the erosion rates along the Arctic coast have been accelerating (Gibbs et al., 2015, 2019; Lantuit et al., 2012), and the length of the ice-free season appears to be directly related to the higher erosion rates (Barnhart et al., 2014). While warmer temperatures are an obvious driver of erosion, in particular in areas with permafrost bluffs, mechanical processes associated with wave activity are likewise considered a leading contribution (Overeem et al., 2011). The effect of coastal sea ice in dissipating large waves and decreasing the magnitude of storm surges is reduced as the open water season lengthens and extends further into the autumn period of increased storminess in the Alaskan Arctic (Atkinson, 2005; Fang et al., 2018). At the same time, a rise in surface wave activity has been observed in the Chukchi and Beaufort Sea (Thomson et al., 2016; Wang et al., 2015), linked to increased fetch distance due 
to larger open water extent during ice-free season (Thomson \& Rogers, 2014). Together, these changes in ice and wave conditions are expected to accelerate Arctic coastal erosion.

Quantifying the role of sea ice presence in coastline protection requires an accurate representation of wave and sea ice interactions, which span a wide range of conditions typical for the coastal Arctic. The complex and potentially nonlinear processes that govern these interactions pose a challenge to both observations and numerical models. In recent years, however, considerable progress has been achieved on both fronts (Squire, 2018). The present study focuses on a set of conditions that are becoming increasingly commonplace. The Alaskan Arctic in autumn is becoming increasingly defined by wave activity, especially conditions of frazil and pancake ice forming in wave fields of 2-3 m significant wave height (Roach et al., 2018; Thomson et al., 2018). Pancake ice is specifically associated with new ice formation in dynamic wave conditions (Doble et al., 2015). Wave attenuation in this type of ice is dominated by dissipative processes (as opposed to scattering, see Kohout \& Meylan, 2008; Squire et al., 1995) and is typically formulated as an exponential decay of spectral wave energy $E(x, f)$ with distance $x$ traveled in ice, that is, $E(x, f)=E(0, f) e^{-\alpha(f) x}$. Here, $\alpha(f)$ is the spectral attenuation coefficient and its quantity is determined by a number of physical mechanisms with varying levels of contribution based on wave and ice conditions. Quantifying these small scale effects using process-based models presents a significant challenge (Shen \& Squire, 1998) and model results are often difficult to reconcile with in situ observations. In operational wave models (WAVEWATCH III, Simulating WAves Nearshore[SWAN]), forecasters sometimes use empirical parametrizations. The one used in this study is denoted as IC4M2 (Rogers, 2019; Rogers et al., 2018; The WAVEWATCH III ${ }^{\circledR}$ Development Group, 2016) and its dissipative attenuation rate $\alpha$ follows a power law in frequency: $\alpha(f) \propto f^{n}$. Coefficients of this function are obtained using the best fit to the $\alpha$ values determined from in situ measurements in the Marginal Ice Zone (MIZ), where waves propagate from open water into ice cover. This relation was demonstrated in four independent field studies by Meylan et al. (2018), who further connected changes in dispersion to the power law dependence of attenuation, assuming only small changes of the wavenumber in ice relative to wavenumber in open water (as recently shown by Collins et al., 2018). Most prior MIZ measurements, and most operational wave models, are predominantly for deep-sea applications and large domains. The applicability of these parametrizations to coastal sea ice in nearshore conditions has not been investigated.

In addition to in situ observations, laboratory experiments using wave tanks provide insight into waveice interactions under controlled and repeatable conditions (Table 1 in Parra et al., 2020 provides a useful overview). Tank measurements of wave dissipation are confined to smaller spatial scales than in situ observations, and typically they report attenuation rates of $10^{-1}-10^{-2} \mathrm{~m}^{-1}$ (Herman et al., 2019; Shen, 2019), which are two or three orders of magnitude larger than those found in field experiments (Doble et al., 2015; Rogers et al., 2016). The additional damping is often attributed to mechanisms associated with the inherent physical constraints of the laboratory setup such as overwash (Meylan et al., 2015), sidewall effects, and properties of the materials simulating the ice cover. However, other wave dissipation field measurements conducted on small spatial scales in the proximity to the ice edge have also reported higher dissipation rates (Asplin et al., 2018; Rabault et al., 2017) that are similar to those obtained in wave tanks.

Here we study a nearshore region of the Chukchi Sea, with water depths ranging from 13 to $30 \mathrm{~m}$. We present an observational dataset capturing a 4-day-long wave event, with an aim to determine the magnitude of cross-shore wave attenuation in coastal pancake and frazil sea ice, and further constrain empirical models for use in coastal applications. Sampling took place at the end of November 2019, when the Chukchi and Beaufort region of Alaska experienced an unusually late onset of winter ice accompanied by increased wave activity. The measurements provide a unique record of the increasingly frequent open water conditions at a time of year when the coastline historically would have been protected by ice. The resulting dataset offers a relatively high spatial resolution (150 m over a 3,000 m transect within sea ice) in close proximity to the ice edge.

In Sections 2.1 and 2.2, we describe our experiment setup and the conditions at the site with an emphasis on wave and sea ice observations. In Section 2.3, we consider the effects of intermediate and shallow depth on our measurements and discuss our approach to evaluating spectral dissipation throughout the event. Section 3 presents apparent spectral attenuation rate with respect to ice type and proximity to ice edge and a 
comparison with past observations in the MIZ. Section 4 provides a discussion of the uncertainty in our ice edge estimate and a brief analysis of the evolution of sea ice and temperature throughout the event.

\section{Methods}

\subsection{Description of Field Experiment}

Data presented in this study were collected over a 4-day period during the Coastal Ocean Dynamics in the Arctic (CODA) research cruise on the $R / V$ Sikuliaq in November 2019 near a barrier island system west of the Icy Cape headland in the Chukchi Sea (Figure 1a). The coastline is shaped by sand and gravel islands and barrier spit extensions from land. The larger Icy Cape region is considered erosional, with average horizontal shoreline change of $-0.4 \mathrm{~m} / \mathrm{yr}$ (Gibbs et al., 2015). Starting on November 21, 2019, a low pressure system passed over the Icy Cape area and created an energetic wind sea, referred to here as a wave event. Drifting coastal and pancake ice was present near the coast, attenuating the incoming wavefield. The cruise objective was to study interactions of ocean surface waves and sea ice in nearshore conditions by means of mooring arrays and opportunistic sampling of surface waves using drifting buoys. Shoreward wave propagation was sampled over a transect of $20 \mathrm{~km}$ using five moorings and six drifting wave buoys, allowing us to observe dissipative effects of ice as a function of proximity to the ice edge.

The array consisted of five moorings positioned in the cross-shore direction at depths increasing from $13 \mathrm{~m}$ to $30 \mathrm{~m}$ and locations $x=5-25 \mathrm{~km}$ (Figure 1b). $x$ here refers to the cross-shore distance from the coast increasing in the positive direction (reverse $x$-axis in Figure 1b). The furthest offshore mooring (denoted as S1A1) was equipped with an Acoustic Doppler profiler (Nortek Signature1000) on a seafloor tripod, sampling waves and currents at $2 \mathrm{~Hz}$. The remainder of the array (labeled S1P1-S1P4) comprised seafloor pressure and temperature loggers (RBR Duet) each with additional temperature loggers (Onset HOBOs) strung along the subsurface moorings. One of the moorings (S1P4) had an additional turbidity sensor and a Surface Wave Instrument Float with Tracking (SWIFT; Thomson, 2012) buoy attached at the surface.

In addition to the continuous mooring observations, several freely drifting SWIFT buoys were deployed from $R / V$ Sikuliaq (Figure $1 b$ ). The goal was to obtain complementary data in the Lagrangian reference frame and cover a range of ice types and conditions relative to the evolving ice edge, as well as to sample the wave activity in the along-shore direction. Six SWIFT buoys were used throughout the experiment, deployed along the cross-shore transect defined by the moorings S1P1-S1A1 and recovered when in need of maintenance or upon drifting too far away from the study site. Each buoy was equipped with an inertial measurement unit, Global Positioning System, and radio and satellite transmitters. Some carried additional instruments including anemometers, cameras, and water and air temperature loggers, providing further insight into the evolution of the wave event.

\subsection{Wave Event}

The observations were collected over the course of a wave event at Icy Cape (Figure 2). The ship arrived at the site as the waves were building, and they peaked at the end of the first day with $3 \mathrm{~m}$ recorded significant wave height $H_{s}$ (integrated over frequency domain $0.0098<f<0.4902 \mathrm{~Hz}$ ). Wave heights remained at approximately $2 \mathrm{~m}$ for the remainder of data collection. Both wind and wave directions were from the northeast and later from the north, with incident wave angle ranging between $40^{\circ}$ and $0^{\circ}$ with respect to the cross-shore direction. Wind speed recorded by the ship-based anemometers varied between 6 and $14 \mathrm{~m} / \mathrm{s}$, peaking on November 21, 2019. The peak wave period increased from $5 \mathrm{~s}$ to $8 \mathrm{~s}$ over the course of the event.

\subsubsection{Sea Ice Measurements}

The type and extent of sea ice during the event is reconstructed from three independent sources: images recorded every $5 \mathrm{~s}$ by cameras mounted on the SWIFT buoys, hourly visual observations from $R / V$ Sikuli$a q$, and Synthetic-aperture radar (SAR) images provided by RADARSAT-2. In addition, a small number of physical samples of pancake and grease ice were collected using dip nets to determine thickness and quality. 
(a)

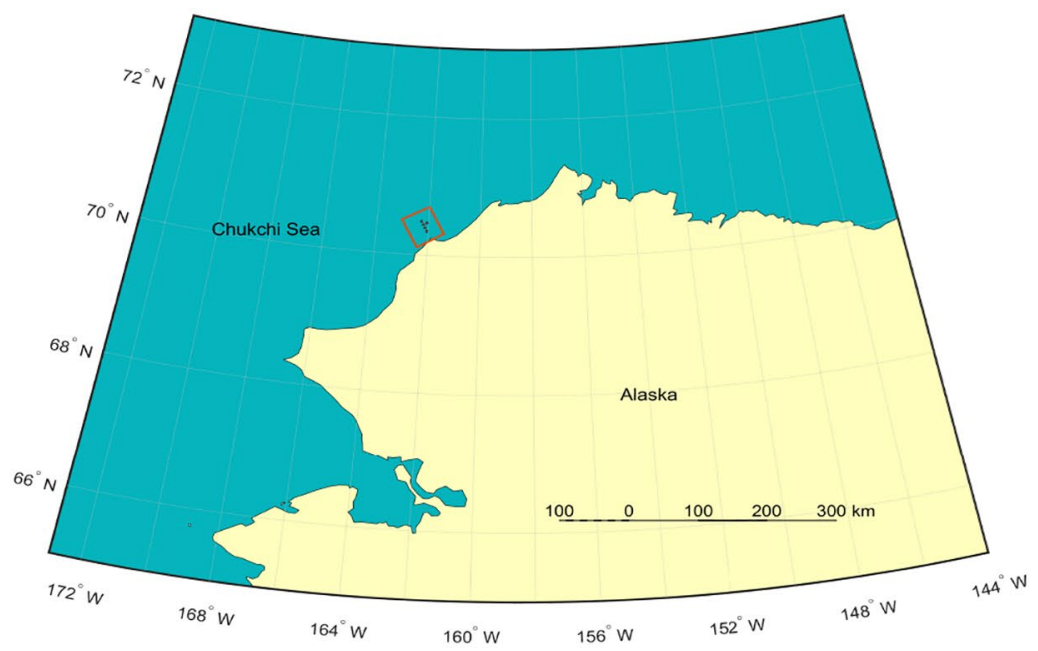

(b)

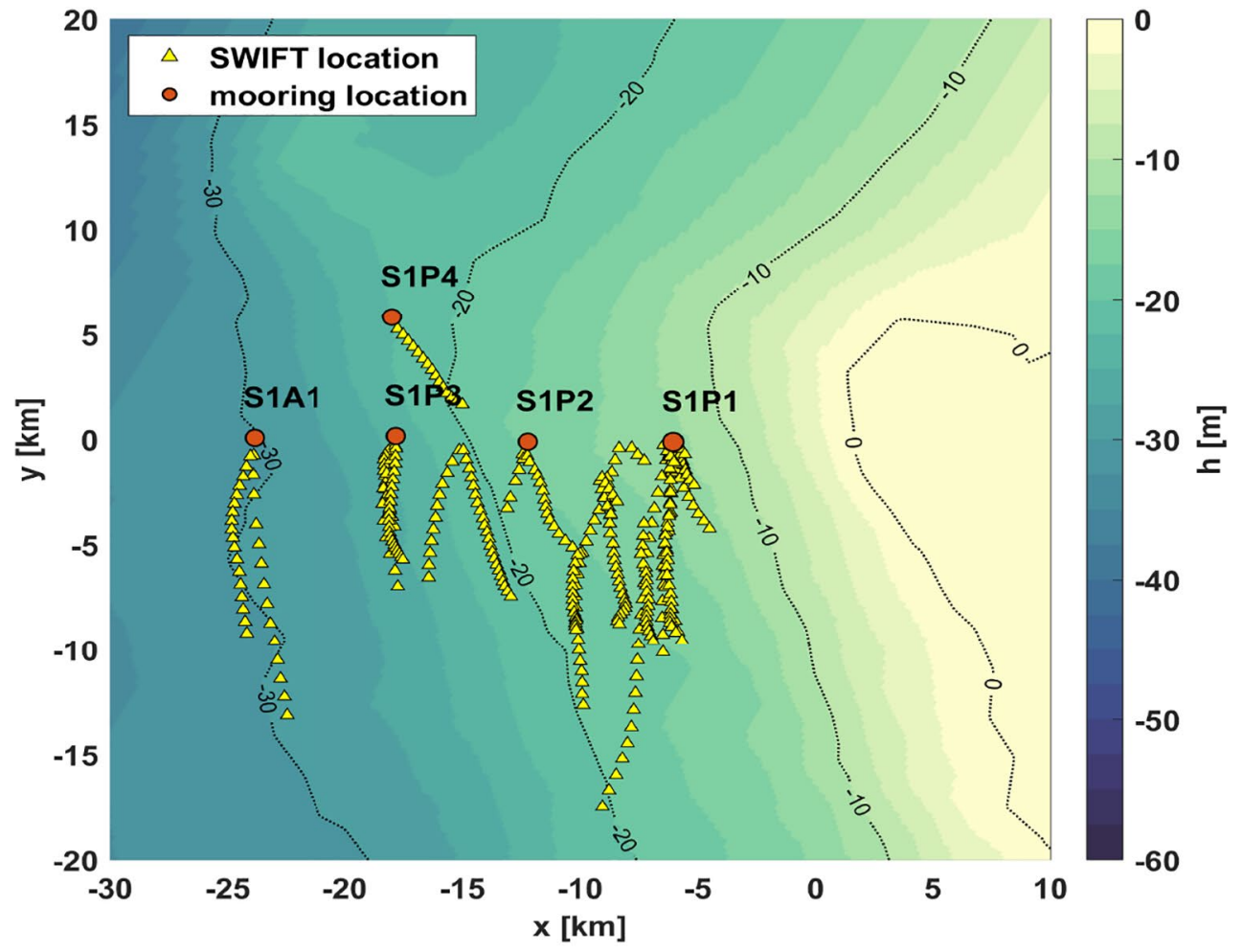

Figure 1. (a) Location of the Icy Cape study site within state of Alaska. (b) Detail of the study site, including a local coordinate system and ocean bathymetry (in meters) of the site obtained from the ETOPO1 dataset (Amante \& Eakins, 2020). Circles represent mooring locations and triangles show trajectories of all drifting wave buoys deployed during the wave event. SWIFT, Surface Wave Instrument Float with Tracking.

During the peak of the event, when pancake ice was most consolidated, the measured thickness of samples ranged between 7 and $10 \mathrm{~cm}$.

SAR images (Figure 3) are used to evaluate the extent and evolution of sea ice. Backscatter characteristics are a measure of surface roughness and depend on the acquisition mode, incidence angle, weather conditions, etc. In this case, ice appears as a bright area in the early (Figure 3a) and late (Figure 3f) Sentinel-1 images, while it appears as a low signal in the four RADARSAT-2 images (Figures 3b-3e), probably because 

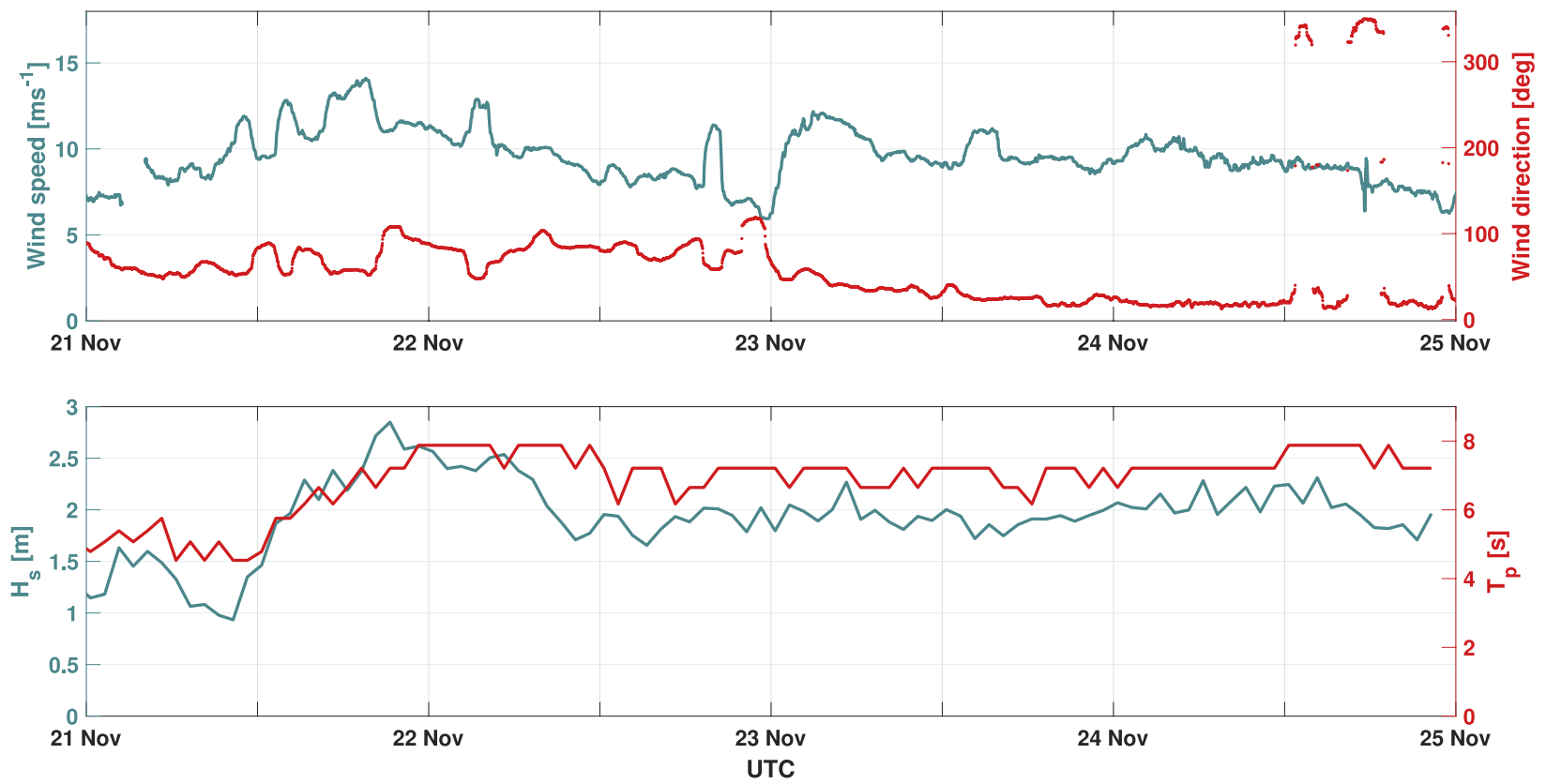

Figure 2. Top: Wind speed (blue) and direction (red) throughout the event wave event at Icy Cape obtained using ship-based anemometers on board $R / V$ Sikuliaq. Bottom: Significant wave height (blue) and wave period (red) recorded at the location of the S1A1 mooring using the Nortek Signature1000.

of the higher sea state in open water. Images obtained on November 20, 22, and 23 show that the ice edge was located between the S1P1 and S1P2 moorings for the duration of our observations, while the images taken after the event on November 25 and 26 suggest that the sea ice retreated and became more patchy.

Cameras mounted on the masts of the SWIFT buoys recorded a low resolution image every $5 \mathrm{~s}$. The images were reviewed manually, and any unusable (i.e., blurry, obscured by icing or darkness) images were discarded. The remaining images were manually analyzed and assigned an integer code on a scale of 0-12 to characterize the ice type. This categorization was introduced in Rogers et al. (2018) and previously applied to observations from the Arctic Sea State Experiment in 2015 (Thomson et al., 2019; see their Table 1). The ice codes range from less to more solid ice, and can be broadly grouped as $0-1$ for open water and possible grease ice, 2-4 for frazil ice, 5-8 for brash ice and small to medium-sized pancakes, and 9-12 for substantial pancake ice. Visual observations (from the ship) of sea ice evolution agree well with the dotted line representing interpolation between RADARSAT-2 ice edge estimates. Collectively these data allow us to quantify the location and type of sea ice throughout the event and to analyze its impact on the incident wavefield in Section 3.

Complementary to drifting cameras, hourly ship-based observations of sea ice were performed according to the Arctic Ship-based Sea Ice Standardization Tool observation protocol (ASSIST). Additionally, information about ice type was logged each time the ship stopped to take measurements. All the above records have been combined into a single dataset presented in Figure 4 (top).

\subsubsection{Wave Measurements}

The measurements of wave activity were collected in both Eulerian (cross-shore mooring array, a SWIFT buoy moored to the sea floor) and Lagrangian reference frame (drifting SWIFT buoys). This setup offers a good overview of the spatial evolution of the event. In particular, data from drifting SWIFT buoys reveal that the direction of surface currents was dominantly alongshore, and none of the quantities considered in our analysis evolved considerably in the drifting reference frame. This provides a good justification for neglecting alongshore coordinate $y$ in the reference frame from Figure $1 \mathrm{~b}$ and confining our analysis to cross-shore direction $x$. 

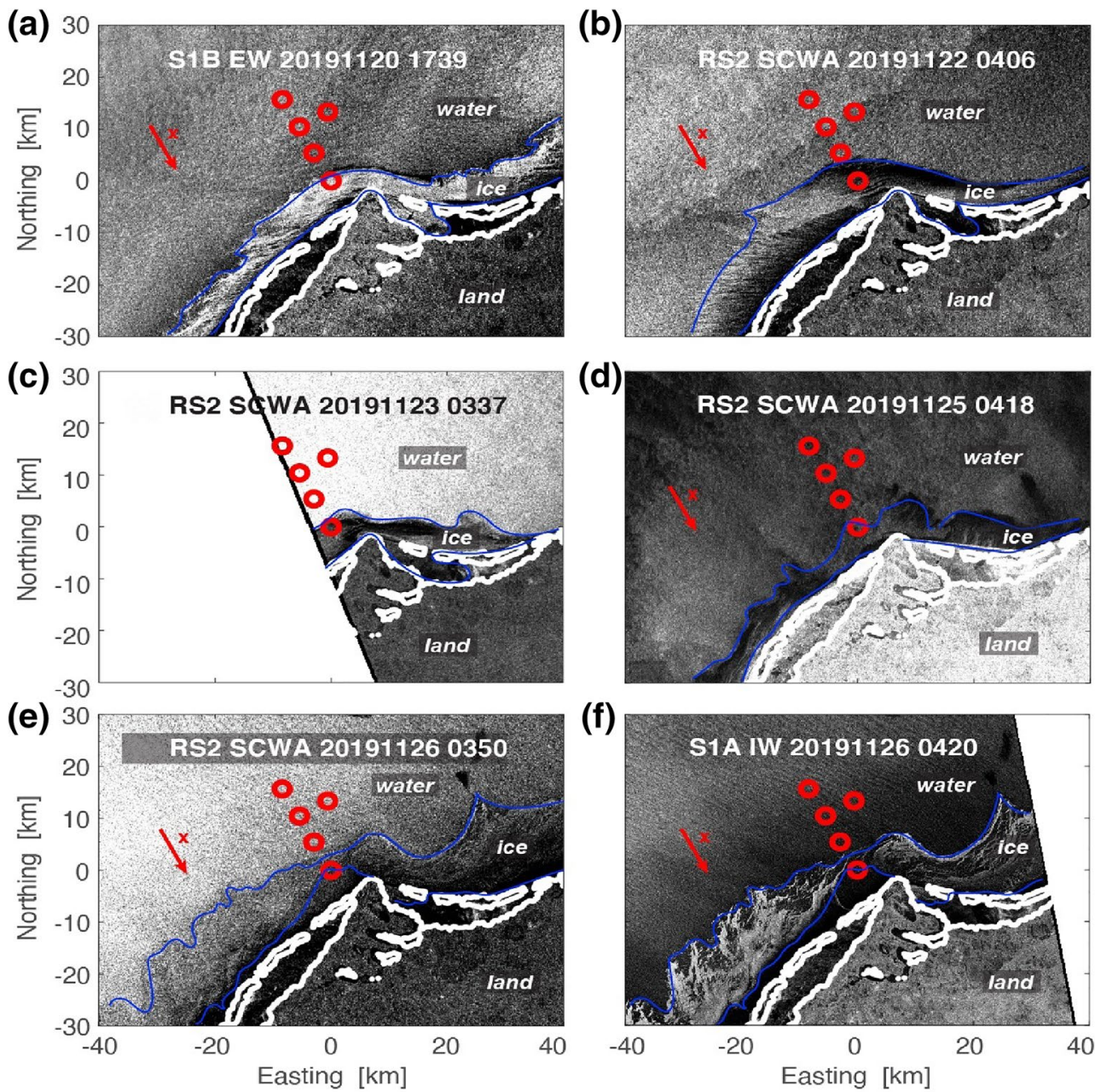

Figure 3. SAR images acquired by Sentinel-1 and RADARSAT- 2 in the Icy Cape area before (a), during (b and c), and after (d-f) the wave event. Satellite, acquisition mode, date, and time are noted. White contours indicate the coast line, and the region interpreted as being ice-covered is contained by the blue contours. Red circles indicate mooring locations. SAR, Synthetic-aperture radar.

Figure 4 (bottom) shows spatial and temporal evolution of the significant wave height calculated using data from all mooring arrays and SWIFT buoys. The event peaked on November 21, 2019 with incident waves reaching $3 \mathrm{~m}$, and slowly died out over the period of the next 3 days. Figure 5 further illustrates the dissipative effect of sea ice at the peak of the event (Phase A), reducing the wave height by $0.7 \mathrm{~m}$ over less than $3 \mathrm{~km}$.

The cross-shore timelines of sea ice and wave evolution offer a useful overview of the event progression (Figure 4). $R / V$ Sikuliaq arrived at the site as the waves were building up on 21 November. Peak of the wave activity started at 16:00 Coordinated Universal Time and lasted for the next $12 \mathrm{~h}$, during which substantial pancake ice was observed. Both wave heights and size of ice floes started to decline on 22 November, as the pancake floes became mushy and unconsolidated. On 23 November, only patches of frazil ice were observed and active deployments of wave buoys were concluded. On the last day of the event we recorded very sparse sea ice presence as the wave activity continued to decrease.

In the following analysis of spectral wave dissipation, we consider only SWIFT buoy measurements collected during phases A, B, and C in Figure 4 to ensure statistical robustness of wave data within the ice cover. Figure 6 shows mean energy density spectra measured in each phase and binned by the distance from the ice edge estimate derived from SAR imagery. 

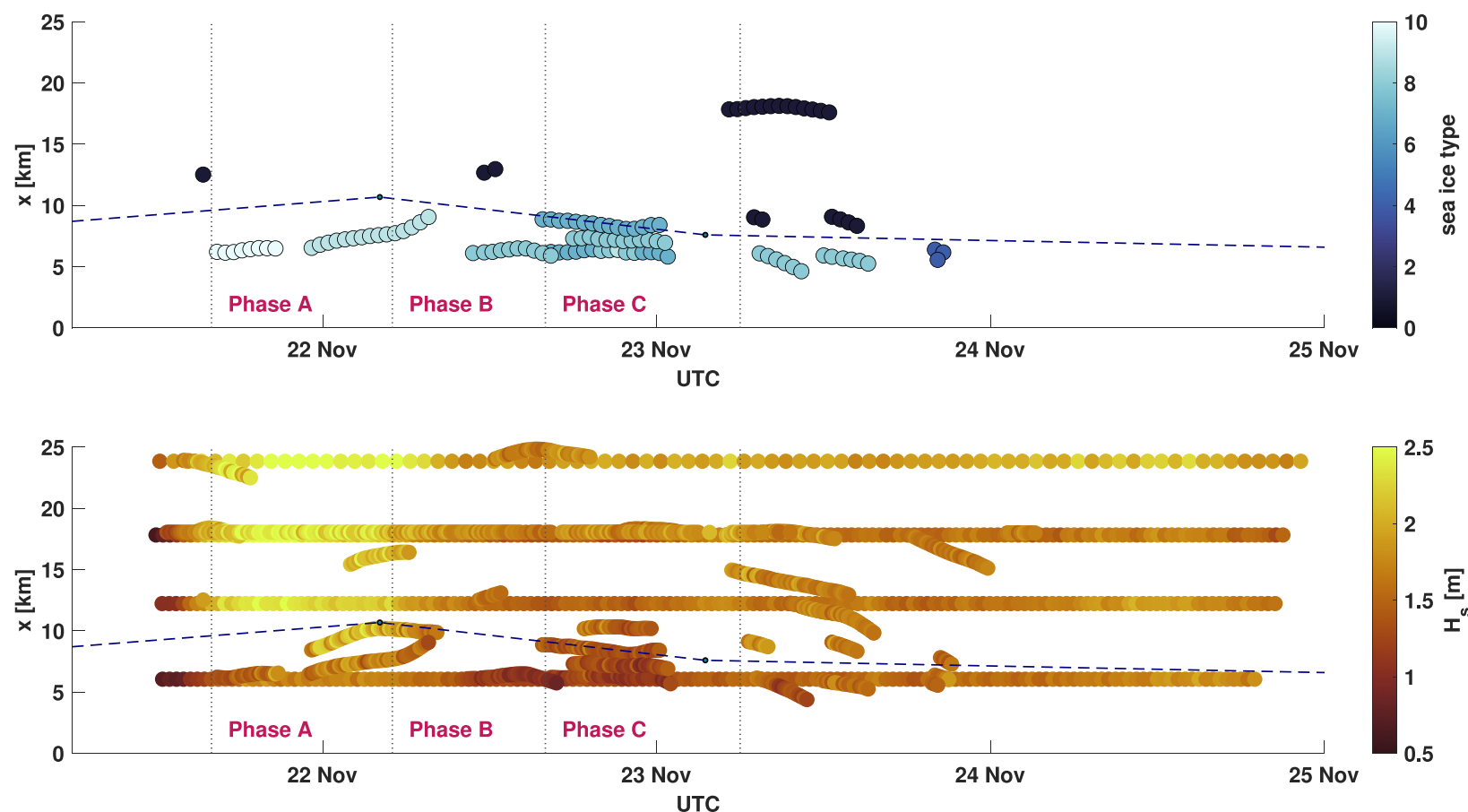

Figure 4. Top: Evolution of sea ice type during the wave event at Icy Cape, as a function of time and cross-shore distance. The plot combines information about ice type from SWIFT mounted cameras and visual observation upon deployment and recovery (colored circles), as well as ice edge location from RADARSAT-2 imagery (markers connected by dashed line). Vertical lines delineate event phases considered in further analysis. Bottom: Evolution of significant wave height during the event as a function of time and cross-shore distance, combining data reported by SWIFT buoys and mooring instruments. SWIFT, Surface Wave Instrument Float with Tracking.

A hard spectral cutoff of $E_{n}(f) / E(f, x)<1 / 10$ has been applied to the data to produce Figure 6 and all further analyses, in order to avoid spurious negative biases in attenuation that originate in instrument noise. $E_{n}(f)$ here is the spectral energy of the noise and has been empirically determined to follow $f^{-4}$ with an equivalent height $H_{n}=0.10 \mathrm{~m}$ that is specific to the instrumentation and post processing method.

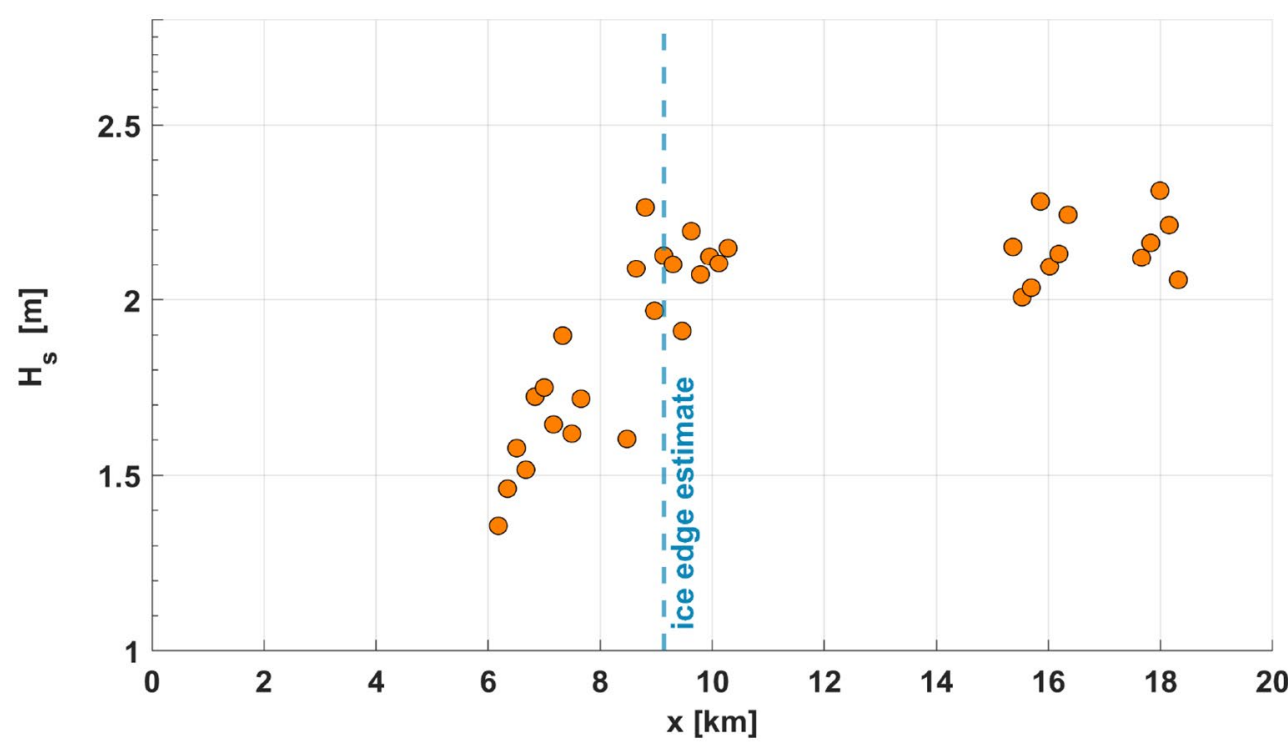

Figure 5. Significant wave height as a function of cross-shore distance at the peak of the event (Phase A). Vertical dotted line represents the ice edge estimate derived from RADARSAT- 2 imagery. Note that the vertical axis starts at $1 \mathrm{~m}$ 

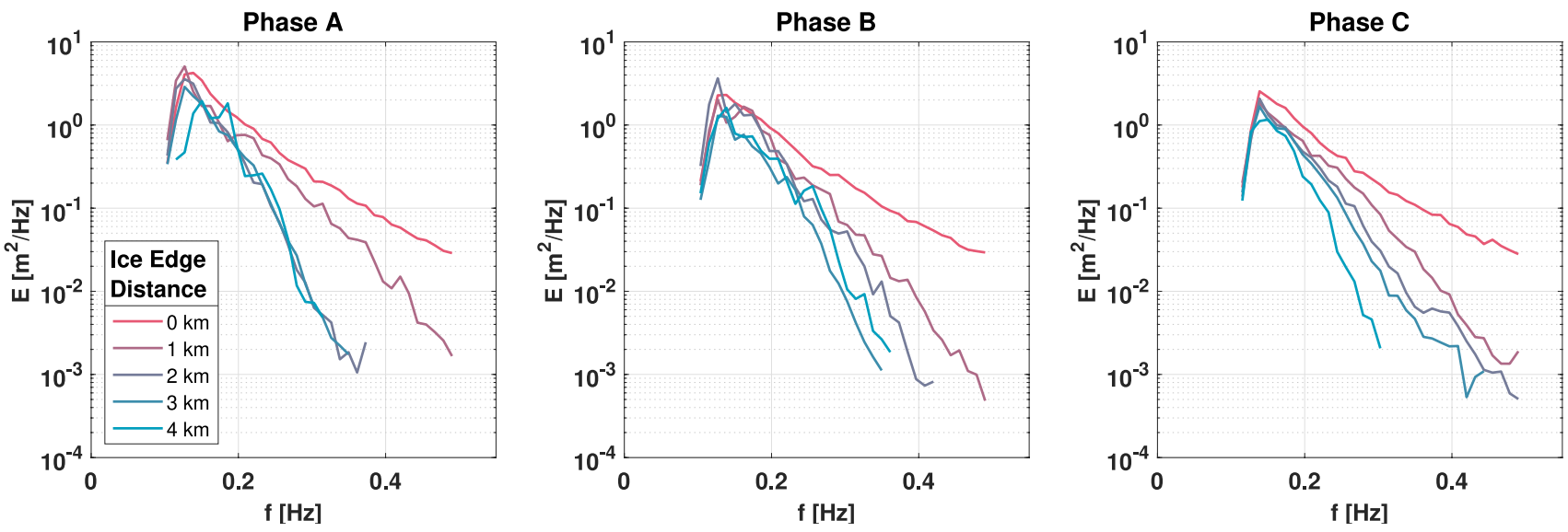

Figure 6. Mean ocean wave spectra binned by distance from the ice edge (line labeled $0 \mathrm{~km}$ represents mean incident spectrum) for phases A, B, and C. Each bin comprises between 1 and 109 spectral estimates, each with 32 underlying degrees of freedom.

Thomson et al. (2020) show that noise can manifest as a flattening, or "rollover," in the high frequency tail of spectral attenuation rates as waves dissipate in the ice and energy density approaches the noise floor. The above cutoff substantially reduces this effect at a cost of discarding a large portion of observations at the high frequency tail, as evidenced in Figure 6 where the lines furthest from the ice edge do not extend across the full frequency range.

\subsection{Analysis of Spectral Energy Dissipation}

\subsubsection{Nearshore Effects}

Effects of wave shoaling and refraction between locations S1P4 and S1P1 (Figure 1b) were estimated to be less than $5 \%$ and $10 \%$, respectively, over the considered time period. The shallow water effect of nonlinearity, relative to dispersion, can be estimated using the Ursell number $U r=\frac{a}{\kappa^{2} h^{3}}$, where $a$ is the wave amplitude, $\kappa$ is the wavenumber magnitude, and $h$ is the water depth (Ursell, 1953). The magnitude of $U r$ at the shallowest observation (water depth $13 \mathrm{~m}$ ) is only 0.2 during the most active phase of the event, indicating that nonlinear triad interactions are weak. We conclude that the effects of intermediate and shallow depths on waves likely played a negligible role compared to the dissipating effects of sea ice. Figure 5 corroborates this by showing a large change in significant wave heights at the ice edge, and no trend outside of the ice.

\subsubsection{Binning Method}

We choose Phases A, B, and C for analysis to categorize conditions that are qualitatively similar with respect to wave activity and sea ice type to ensure statistical stationarity. All quantities observed in a given phase are considered to be representative and their variance in time is neglected.

To further simplify our analysis and increase sample size, we divide the ice covered area into equidistant intervals along the $x$-axis, and bin average available wave data to obtain $E_{i}(f)=\bar{E}\left(f, x \in\left\langle x_{i}, x_{i+i}\right\rangle\right)$ , where $i$ denotes the bin number and $x_{i}$ refers to delimiters of the intervals. Throughout this section, the bin size is set to $\delta x=150 \mathrm{~m}$, chosen as the best compromise between spatial resolution and robustness of the data.

The location of the ice edge $x_{0}$ is set to the mean distance interpolated from the SAR imagery for each phase of the event, combined with available in situ observations from the ship log and cameras on the SWIFT buoys. The incident wavefield is obtained as the mean spectral energy density of all measurements where $x>x_{0}, E_{0}(f)=\left.\bar{E}(f)\right|_{\{x\}>x_{0}}$. 


\subsubsection{Attenuation Coefficient}

In one dimension, we can express attenuation of the directional spectral energy density $E_{0}$ across above defined bins as

$$
E_{i}(f)=E_{0}(f) e^{-\alpha_{i}(f) \Delta x_{i}}
$$

where $\Delta x_{i}=x_{0}-x_{i}+\delta x / 2$ corresponds to the mid-distance of the bin from the ice edge $x_{0}, \alpha$ is the attenuation coefficient and $E_{i}$ is the mean spectral density within bin $i$.

Correcting for the mean incident angle $\theta$ of the wave direction with respect to the $x$ axis, the attenuation coefficient for bin $i$ is

$$
\alpha_{i}(f)=\frac{\cos \theta}{\Delta x_{i}} \ln \frac{E_{0}(f)}{E_{i}(f)}
$$

\section{Results}

\subsection{Spectral Attenuation Rates}

In all three phases, we see a strong dependence of attenuation on the distance from the ice edge. In particular, the values of $\alpha(f)$ in the first three bins (corresponding to approximately $500 \mathrm{~m}$ distance from the ice edge) are substantially higher than in the farther bins (Figure 7). The left plot (Figure 7) shows values of $\alpha$ within $500 \mathrm{~m}$ from the ice edge $\left(\alpha_{<500}\right)$, while the middle plot shows attenuation coefficients farther in the ice $\left(\alpha_{>500}\right)$. While the uncertainties of $\alpha_{<500}$ are large due to the comparative scarcity of wave data, there is a clear indication that the proximity to the ice edge plays a significant role in the dissipation rate across all three phases. Meanwhile, the differences between phases and associated ice types ranging from solid pancake ice in Phase A to frazil ice in Phase $\mathrm{C}$ all lie within the standard error of the mean, obscuring any indications regarding their relative effects on the wavefield. Combining data from all three event phases while distinguishing only by proximity to ice edge (Figure 7, right) reduces the uncertainty and shows the attenuation rate $\alpha_{<500}$ to be approximately three times higher than $\alpha_{>500}$. The dotted lines in Figure 7 show inferred attenuation rates from other studies and are discussed in more detail below.

Despite the stronger attenuation near the ice edge, there are no indications of reflections or refraction at the ice edge. No visible standing wave patterns were observed from the ship during the experiment, and there are no changes in the wave directional distributions (as given by the standard spectral moments, see Kuik et al., 1988) as a function of position relative to the ice edge.
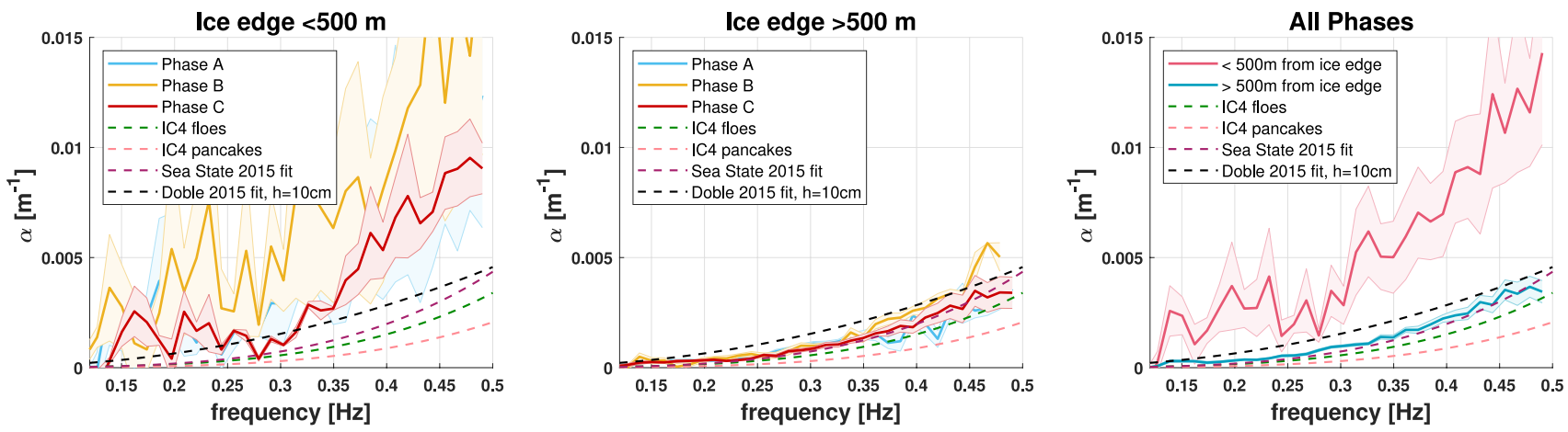

Figure 7. Attenuation coefficients at the Icy Cape wave event. Dashed lines show Simulating WAves Nearshore (SWAN) IC4M2 parametrizations (Rogers, 2019), polynomial fit of Sea State 2015 dataset (Cheng et al., 2017), and a power law fit from (Doble et al., 2015) using equivalent ice thickness of $10 \mathrm{~cm}$. Shaded areas represent standard error of the mean taken over considered bins. Left: Attenuation coefficient during phases A, B, and C using bins within $500 \mathrm{~m}$ of the ice edge. Center: Attenuation coefficient during phases A, B, and C using bins farther than $500 \mathrm{~m}$ of the ice edge. Right: Attenuation coefficient averaged over phases $\mathrm{A}, \mathrm{B}$, and $\mathrm{C}$. 


\subsection{Comparison with Existing Datasets}

A number of existing field observations of wave dissipation in pancake and frazil ice, both in the Southern Ocean and more recently in western Arctic, allow us to discuss the above results in a wider context. While the magnitudes of the attenuation reported by comparable experiments span several orders of magnitude $\left(10^{-3}<\alpha(f)<10^{-5}\right)$, the spectral behavior for loose, noncompact sea ice generally follows a power law fit $\alpha \propto f^{n}$ with $n$-values falling between 2 and 4, or a two-term polynomial fit $\alpha=a f^{2}+b f^{4}$ proposed by Meylan et al. (2014). In Figure 8, we have explored these options, along with a power law with an offset $\left(\alpha=a f^{b}+c\right)$ while distinguishing between data collected near and further from the ice edge. In both cases, all three formulas produce nearly identical fits using the nonlinear least squares method.

Wave dissipation data collected during the Sea State campaign in the Beaufort Sea during autumn 2015 (Cheng et al., 2017) provide a convenient comparison. The wave and ice conditions as well as instruments bear many similarities to the Icy Cape observations, even though the Sea State cruise sampled farther offshore in the deep-water MIZ. The Sea State 2015 results, using the formula $\alpha=a f^{3}+b f^{4}$, are shown as a purple dashed line in Figure 8. The new CODA 2019 results described herein are the solid lines, and they agree well in the region $>500 \mathrm{~m}$ from the ice edge. However, in the region $<500 \mathrm{~m}$ from the ice edge, our new results exceed those previous dissipation estimates by a factor of three.

Comparatively higher dissipation rates have been reported by Doble et al. (2015), using a 12-day period of observations of pancake ice by an array of wave buoys in the Weddell Sea. The study proposes a power law fit to frequency with a coefficient dependent on the equivalent ice thickness, obtained from observed thickness by accounting for porous volume within pancake and frazil ice. While our measurements of sea ice samples do not account for porosity, they can be considered an upper bound on the solid ice equivalent for the purpose of comparison. The black dashed line in Figure 8 represents a power law fit using the highest observed sea ice thickness, $10 \mathrm{~cm}$. While higher than the Sea State attenuation rates, the estimates using this fit are consistent with the data collected in the region farther from the ice edge. They do not, however, reflect the sensitivity of the observations to the ice edge proximity, nor the consistency of the apparent attenuation rates between ice types with different porosities. Application of the power law fit from Doble et al. (2015) to our dataset shows that the equivalent ice thickness needed to match $\alpha_{<500}$ is $29 \mathrm{~cm}$.

The other two dashed lines in Figure 8 show the shapes of two empirical parametrizations used in WAVEWATCH III (Rogers et al., 2018; The WAVEWATCH III ${ }^{\circledR}$ Development Group, 2016) and SWAN wave models (Rogers, 2019) to represent dissipation effects of sea ice on waves, distinguishing broadly between ice floes (defined as between 10 and $25 \mathrm{~m}$ in diameter) and pancake ice. These parametrizations (denoted
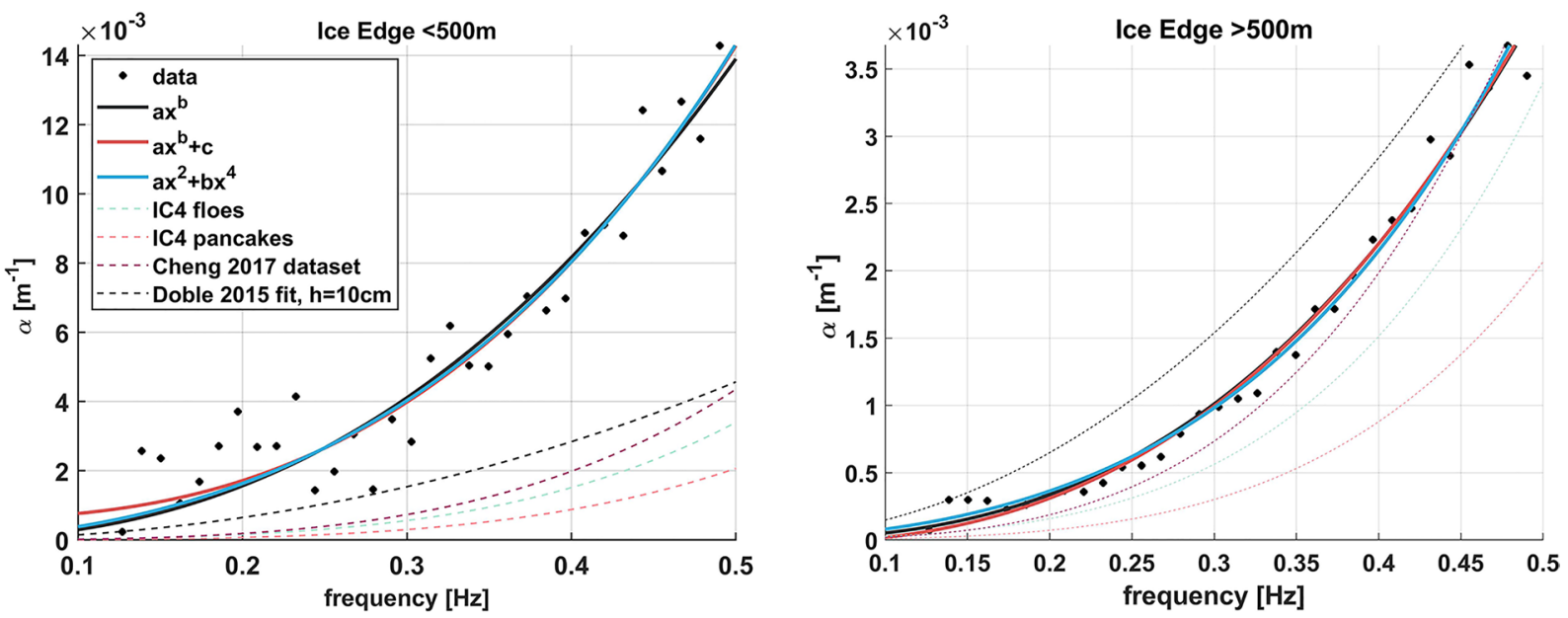

Figure 8. Selected polynomial fits to attenuation coefficients measured within and past $500 \mathrm{~m}$ distance from the ice edge, compared with IC4M2

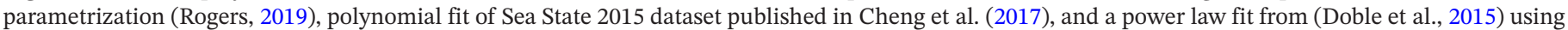
equivalent ice thickness of $10 \mathrm{~cm}$. 
Table 1

Parameter Estimates of the Polynomial Fits for $\alpha(f)$ in Figure 8 Evaluated Using the Nonlinear Least Squares Method, Along With 95\% Confidence Interval

\begin{tabular}{lll}
\hline Fitting formula & \multicolumn{1}{c}{ Ice edge $<500 \mathrm{~m}$} & \multicolumn{1}{c}{ Ice edge $>500 \mathrm{~m}$} \\
\hline$a f^{b}$ & $a=0.072(0.048,0.097)$ & $a=0.026(0.022,0.030)$ \\
& $b=2.3(2.0,2.8)$ & $b=2.7(2.5,2.9)$ \\
& $R^{2}=0.91$ & $R^{2}=0.99$ \\
$a f^{b}+c$ & $a=0.091(0.038,0.14)$ & $a=0.026(0.02,0.032)$ \\
& $b=2.7(1.9,3.5)$ & $b=2.7(2.4,3)$ \\
& $c=6 \times 10^{-4}\left(-5.3 \times 10^{-4}, 1.7 \times 10^{-3}\right)$ & $c=-3.4 \times 10^{-5}\left(-1.6 \times 10^{-4}, 1 \times 10^{-4}\right)$ \\
& $R^{2}=0.92$ & $R^{2}=0.99$ \\
$a f^{2}+b f^{4}$ & $a=0.038(0.026,0.049)$ & $a=0.0076(0.0062,0.0091)$ \\
& $b=0.078(0.015,0.14)$ & $b=0.036(0.028,0.044)$ \\
$R^{2}=0.92$ & $R^{2}=0.98$ \\
\hline
\end{tabular}

Note. $R^{2}$ represents a measure of goodness of fit.

IC4M2 in both models) follow similar frequency dependence as our best fits albeit smaller in magnitude, in particular the "pancake" option which would be considered representative of the conditions at Icy Cape. We conclude that the data obtained is consistent with the IC4M2 parametrizations, and might be used to further constrain the wave models. Table 1 summarizes fitting parameters used in generating these curves, along with their confidence intervals.

Figures 7 and 8 suggest that the proximity to the ice edge plays a dominant role in the magnitude of wave dissipation. While the variability in $\alpha$ could be partially explained by inhomogeneity of the ice cover and uncertainty in our ice edge estimate, this signal remains consistent throughout all analyzed wave conditions and ice types. This suggests that the attenuation of the incident wavefield is not constant throughout the ice cover, and disproportionately larger energy loss occurs in the vicinity of the ice edge. While our data offer no indication of what physical processes might cause this effect, this result is consistent with visual observations where waves undergo almost instantaneous damping in high frequencies as they travel past the ice edge. However, this visual observation may merely reflect the high dissipation rate of higher frequencies in general, which is ubiquitous in this and similar studies. The more novel feature of our results is that they indicate faster dissipation near the ice edge at all frequencies. Most previous field studies have far less spatial resolution (e.g., buoy spacing of $10 \mathrm{~km}$ in Sea State 2015) compared with the present study, and thus it is possible that similar differences near the ice edge were obscured.

Differences in attenuation rates in Figure 7 challenge our assumption that $\alpha(f)$ in Equation 1 is homogeneous across the ice cover. Squire (2018) suggests that Equation 1 can be replaced with a more generalized (nonlinear) form $d_{x} E=-\alpha E^{n}$ to address existing issues of fitting exponential function to observational data. In particular, several experiments (Kohout et al., 2014; Montiel et al., 2018) suggest that wave heights exceeding $3 \mathrm{~m}$ reduce linearly rather than exponentially. This implies a reduction of linear exponential growth rate for larger wave heights. This is qualitatively reversed from the situation at Icy Cape, in which the dissipation is higher nearer the ice edge, where wave heights are largest. However, there are a few caveats. First, wave heights in the present case are below 3 m, where Kohout et al. (2014) and Montiel et al. (2018) predict linear exponential decay. Second, our analysis indicates reduction of attenuation coefficients with $x$; we do not explicitly compute dependence on wave height. Lastly, determination of nonlinearity from field measurements is fraught with the difficultly of isolating wave energy as a variable: correlation may result from indirect causation or coincidence. The most obvious confounding variable is ice type or condition, which is affected by energy level, and in turn affects dissipation. Also, if large wave heights correlate with longer waves, studies which compute dissipation without looking at spectral dependence will tend to conclude that dissipation rate decreases with wave height, as discussed in Liu et al. (2020). 


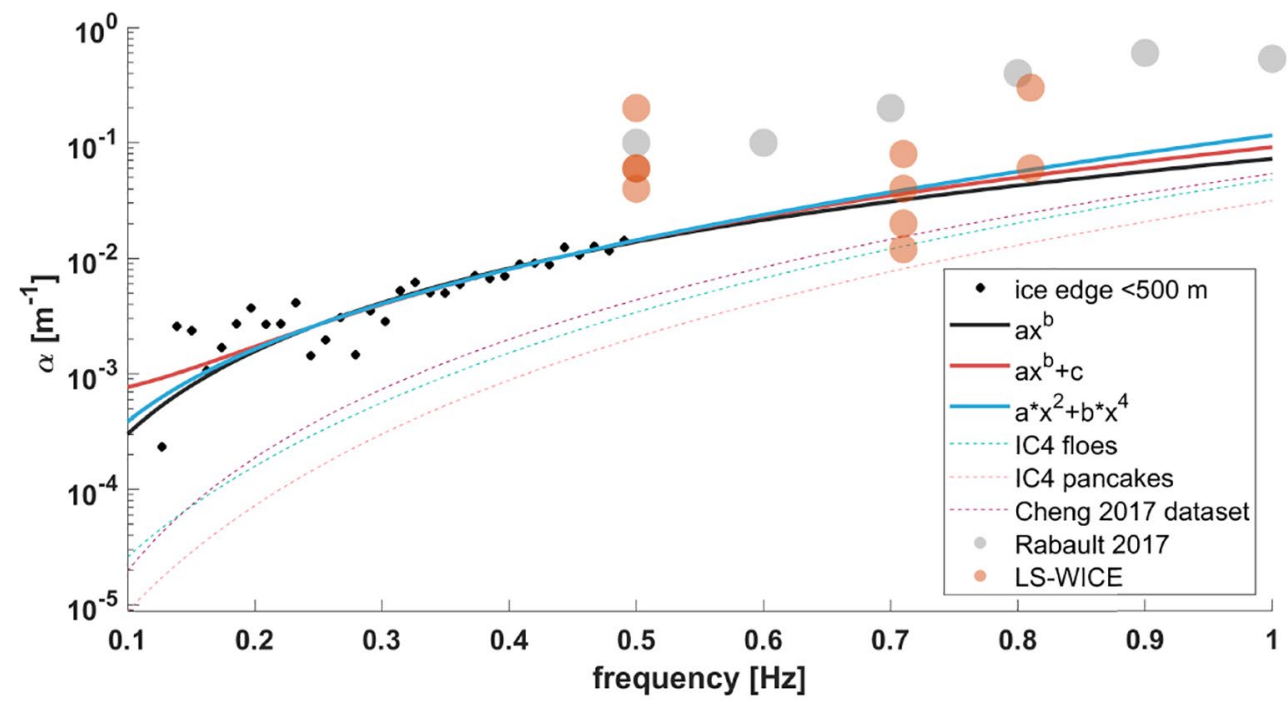

Figure 9. Polynomial fits for $\alpha(f)$ observed within $500 \mathrm{~m}$ from the ice edge from Figure 8 compared to selected observations near the ice edge: grease ice slick in Svalbard (Rabault et al., 2017) and LS-WISE wave tank experiment using $0.5 \mathrm{~m}$ and $1.5 \mathrm{~m}$ diameter floes (Cheng et al., 2019; Herman et al., 2019). Marker locations are approximate, and their size does not reflect measurement uncertainties. Dashed lines show SWAN IC4M2 parametrizations (Rogers, 2019) and polynomial fit of Sea State 2015 dataset (Cheng et al., 2017).

\section{Discussion}

The attenuation of waves approaching the Arctic coasts has broad implications for a range of coastal processes and practical applications. The ability of wave forecast models to predict this attenuation is dependent on both a skilled understanding of what happens right at the ice edge (and ability to determine where the ice edge is located), as well as an understanding of the coupled processes by which the waves and ice evolve. Here we discuss both issues.

\subsection{Dissipation near the Ice Edge}

We have investigated the possibility that the difference between $\alpha_{>500}$ and $\alpha_{<500}$ is a spurious result of our analysis. In particular, our estimate of the ice edge location predominantly relies on our interpretation of the first three SAR images in Figures 3a-3c, in addition to in situ observations obtained from ship logs and SWIFT cameras. While this behavior is found in all three phases considered, the uncertainty of our ice edge estimate and the temporal averaging might prevent us from fully resolving effects on the scale of $500 \mathrm{~m}$. We attempted to reduce this uncertainty by focusing on a $4 \mathrm{~h}$ time window around the satellite image on 22 November (Figure 3) which provides our best estimate of the farthest cross-shore location of the ice edge during the peak of the event. While the dataset confined in this smaller time window is not sufficiently robust to allow full analysis similar that in Section 3 (only a small number of cross-shore bins are populated with data), the same effect is observed, even though it is largely confined to the bin nearest to the ice edge, that is, within the first $150 \mathrm{~m}$. This is consistent with the supposition that the bulk of the damping occurs immediately after the waves enter the ice cover. The range of $500 \mathrm{~m}$ reported in our full analysis could be a result of a "smearing" effect originating in the temporal averaging and uncertainty in ice edge location. To fully explore whether this effect is real and the physical processes involved would require a more persistent observation at the ice edge with even higher spatial resolution.

The higher dissipation rates near the ice edge are qualitatively consistent with laboratory studies which measure dissipation near the ice edge inherently (e.g., Cheng et al., 2019; Herman et al., 2019; Parra et al., 2020), and prior field measurements of dissipation over small spatial scales (e.g., Asplin et al., 2018; Rabault et al., 2017). Direct comparisons with these measurements are often complicated by the lack of overlap in the frequency ranges, the scale of the experimental setup, and the difference in ice type. Figure 9 


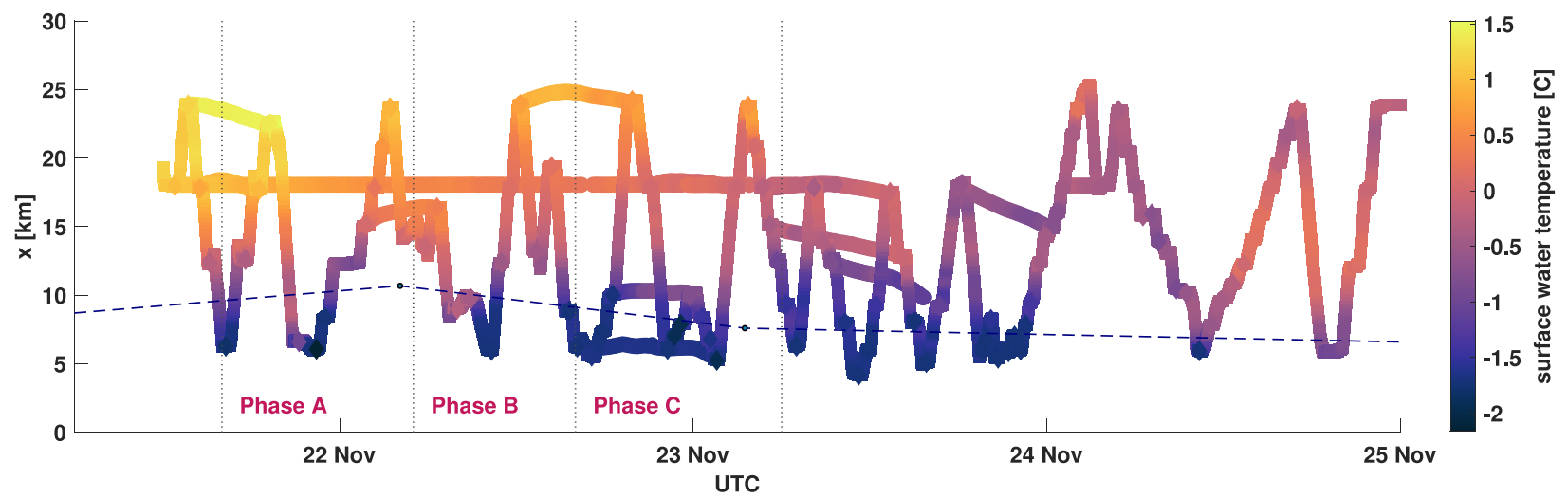

Figure 10. Top: Evolution of surface water temperature during the wave event at Icy Cape as a function of cross-shore distance and time. The plot combines information from SWIFT buoys, flow-through temperature sensor on the $R / V$ Sikuliaq and temperature recorded in the top $1 \mathrm{~m}$ of ship-based Conductivity, Temperature, Depth casts. Dashed line representing sea ice extent estimate is added for reference. SWIFT, Surface Wave Instrument Float with Tracking.

shows selected attenuation rates from two above studies, contrasted with the fits to $\alpha_{<500}$ from Table 1 , as well as the Sea State 2015 and ICM4 fits. The studies were selected due to comparable ice types and floe size. LS-WICE is a tank experiment observing waves propagating through densely packed colliding sea ice floes (sizes $0.5 \mathrm{~m}$ and $1.5 \mathrm{~m}$ shown in Figure 9). Rabault et al. (2017) analyze wave dissipation observed in a grease ice slick near the shore of Svalbard with an array of Inertial Motion Units. In both studies, the waves were observed at a distance of $\Delta x \sim 10^{1} \mathrm{~m}$ from the ice edge. The reported attenuation rates are found to be 1-2 orders of magnitude higher than those found in large scale field experiments (such as Sea State 2015), and approximately one order of magnitude higher than those found within $\Delta x \sim 10^{2} \mathrm{~m}$ from the ice edge in the present study. These discrepancies could be explained by higher attenuation rates immediately near the ice edge, because values of $\alpha$ are inversely proportional to $\Delta x$ (see Equation 2).

\subsection{Evolution of Sea Ice and Sea Surface Temperature}

Figure 4 indicates that both sea ice coverage and type changed rapidly during the event and that this ultimately had the dominant impact on the wave energy in the nearshore. Ice type transitioned from consolidated pancakes $10 \mathrm{~cm}$ thick at the beginning of the wave event to patches of grease ice toward the end, while the ice edge retreated shoreward past our instrument range. Sea surface temperature measurements show a strong cross-shore gradient, with freezing temperatures coinciding with the ice edge (Figure 10) and remaining above freezing in the open water during the initial stages. In later phases the sea ice retreated while the temperature difference decreased, although the air temperature remained well below freezing. We estimated that the net surface heat flux remained negative despite the sea ice retreat, albeit with an increase from approximately $-200 \mathrm{~W} / \mathrm{m}^{2}$ to $-100 \mathrm{~W} / \mathrm{m}^{2}$ in the nearshore in later stages. Remote sensing imagery in Figure 3 suggests that the ice coverage in the broader Icy Cape region was patchy during and after the event. Combining the patterns of sea surface temperature and satellite imagery, it seems likely that the ice retreat at Icy Cape was caused by a combination of advection and local melting. Intrusion of warmer water was detected at $20 \mathrm{~m}$ depth on the third day of the event. We speculate that such temporary ice retreats might be a common episodic phenomenon during the autumn freeze up, with associated effects on wave attenuation (or lack thereof).

The presence of sea ice in the vicinity of Arctic coast has a leading order effect on shoreline erosion (Barnhart et al., 2014). As the duration of the open water season in the area increases, so does the sensitivity of the coastlines to storm surges in the autumn months. In 2019, the onset of coastal sea ice in the observed area was uncharacteristically late, leaving the shoreline exposed to wave events, such as the one documented in this study, all through November. The above discussion suggests that oceanographic processes may be as important as the local surface heat fluxes to determining the presence and fate of ice. This implies that coupled ocean-sea ice models might be necessary to reliably predict the cross-shore propagation of wave energy flux (which is determined by $\alpha$ ) in this region. 


\section{Conclusions}

The following conclusions are made from our analysis:

- Spectral energy dissipation in pancake and frazil ice measured $>500 \mathrm{~m}$ from the ice edge is consistent with published observations of similar conditions

- Higher attenuation rates are observed near the ice edge, suggesting that a linear exponential attenuation formula may not be valid universally across the ice cover. Further measurements capable of resolving wave activity in the immediate proximity of the ice edge are needed to understand this effect and underlying physical processes

- Power dependence on frequency is found to be consistent across the ice cover, even though coefficients of proportionality are not

- Spectral attenuation rates observed during the event are compatible with the IC4M2 parametrization scheme used in WAVEWATCH III and SWAN and can be applied to constrain these wave models

- Coupled ocean-wave-sea ice models might be necessary to represent the evolution of nearshore ice and wave conditions in the autumn season due to complexity of the interplay between thermodynamic and oceanographic drivers

These results may be applied on synoptic, seasonal, and decadal time scales to understand the diminishing protection of Arctic coasts by sea ice and the increasing potential for wave-driven coastal erosion.

\section{Data Availability Statement}

Sentinel-1 data was obtained from the Copernicus Data Hub, supported by the European Space Agency. SWIFT buoy data are available from http://hdl.handle.net/1773/46587 and from the Rolling Deck to Repository (R2R) archive for the Coastal Ocean Dynamics in the Arctic (CODA) 2019 cruise (https://doi. org/10.7284/908599).

\section{Acknowledgments}

We thank our friend and colleague, Nirni Kumar, for the countless contributions he made to this work and beyond. We miss him dearly. We thank engineer Alex de Klerk for preparing, maintaining, and deploying the moorings and SWIFT buoys, and John Malito and Robert Mills for help with deployments and recoveries throughout the wave event. We thank the captain and crew of $R / V$ Sikuliaq, as well as the ship's marine technicians for their support. We kindly thank John and Becca Guillote from Onpoint Outreach for documenting our work on www. iceinmotion.com. Lucia Hošeková, Nirnimesh Kumar, and Jim Thomson were funded by US National Science Foundation (OPP 1818485). Co-author Erick Rogers was funded by the Office of Naval Research, Program Element 0601153N, Document number N0001420WX01935. Lettie Roach was supported by the US National Science Foundation (PLR-1643431). RADARSAT-2 Data and Products are under a copyright of MDA Geospatial Services Inc. 2019-All Rights Reserved, obtained via the U.S. National Ice Center. RADARSAT is an official mark of the Canadian Space Agency.

\section{References}

Amante, C., \& Eakins, B. (2020). ETOPO1 1 arc-minute global relief model: Procedures, data sources and analysis. NOAA: NOAA Technical Memorandum NES-DIS NGDC-24. National Geophysical Data Center. Retrieved from https://www.ngdc.noaa.gov/mgg/global/; https://doi.org/10.7289/V5C8276M

Asplin, M. G., Marko, J., Fissel, D. B., \& Borg, K. (2018). Investigating propagation of short-period ocean waves into the periphery of Arctic pack ice using high-resolution upward-looking sonar. Atmosphere-Ocean, 56(3), 152-161. https://doi.org/10.1080/07055900.2018.1498 765

Atkinson, D. E. (2005). Observed storminess patterns and trends in the circum-Arctic coastal regime. Geo-Marine Letters, 25(23), 98-109.

Barnhart, K. R., Overeem, I., \& Anderson, R. S. (2014). The effect of changing sea ice on the physical vulnerability of Arctic coasts. The Cryosphere, 8(5), 1777-1799. https://doi.org/10.5194/tc-8-1777-2014

Cheng, S., Rogers, W. E., Thomson, J., Smith, M., Doble, M. J., Wadhams, P., et al. (2017). Calibrating a viscoelastic sea ice model for wave propagation in the Arctic fall marginal ice zone. Journal of Geophysical Research: Oceans, 122(11), 8770-8793. https://doi. org/10.1002/2017JC013275

Cheng, S., Tsarau, A., Evers, K.-U., \& Shen, H. (2019). Floe size effect on gravity wave propagation through ice covers. Journal of Geophysical Research: Oceans, 124(1), 320-334. https://doi.org/10.1029/2018JC014094

Collins, C. O., Doble, M., Lund, B., \& Smith, M. (2018). Observations of surface wave dispersion in the marginal ice zone. Journal of Geophysical Research: Oceans, 123(5), 3336-3354. https://doi.org/10.1029/2018JC013788

Doble, M. J., De Carolis, G., Meylan, M. H., Bidlot, J.-R., \& Wadhams, P. (2015). Relating wave attenuation to pancake ice thickness, using field measurements and model results. Geophysical Research Letters, 42(11), 4473-4481. https://doi.org/10.1002/2015GL063628

Fang, Z., Freeman, P. T., Field, C. B., \& Mach, K. J. (2018). Reduced sea ice protection period increases storm exposure in Kivalina, Alaska. Arctic Science, 4(4), 525-537. https://doi.org/10.1139/as-2017-0024

Forbes, D. (2011). State of the Arctic coast 2010: Scientific review and outlook, Geesthacht: Helmholtz-Zentrum.

Gibbs, A. E., Nolan, M., Richmond, B. M., Snyder, A. G., \& Erikson, L. H. (2019). Assessing patterns of annual change to permafrost bluffs along the north slope coast of Alaska using high-resolution imagery and elevation models. Geomorphology, 336, 152-164. https://doi. org/10.1016/j.geomorph.2019.03.029

Gibbs, A. E., Ohman, K. A., \& Richmond, B. M. (2015). National assessment of shoreline change-A GIS compilation of vector shorelines and associated shoreline change data for the north coast of Alaska. U.S.-Canadian border to Icy Cape (Open-File Report No. 2015-1030). U.S. Geological Survey. http://dx.doi.org/10.3133/ofr20151030

Herman, A., Cheng, S., \& Shen, H. H. (2019). Wave energy attenuation in fields of colliding ice floes-Part 2: A laboratory case study. The Cryosphere, 13(11), 2901-2914. https://doi.org/10.5194/tc-13-2901-2019

Kohout, A. L., \& Meylan, M. H. (2008). An elastic plate model for wave attenuation and ice floe breaking in the marginal ice zone. Journal of Geophysical Research, 113(C9), C09016. https://doi.org/10.1029/2007JC004434

Kohout, A. L., Williams, M. J. M., Dean, S. M., \& Meylan, M. H. (2014). Storm-induced sea-ice breakup and the implications for ice extent. Nature, 509, 604. http://dx.doi.org/10.1038/nature13262 
Kuik, A. J., Vledder, G. P. V., \& Holthuijsen, L. H. (1988). A method for the routine analysis of pitch-and-roll buoy wave data. Journal of Physical Oceanography, 18, 1020-1035.

Lantuit, H., Overduin, P. P., Couture, N., Wetterich, S., Are, F., Atkinson, D., et al. (2012). The Arctic coastal dynamics database: A new classification scheme and statistics on Arctic permafrost coastlines. Estuaries and Coasts, 35(2), 383-400. Retrieved from http://www. jstor.org/stable/41486638

Liu, Q., Rogers, W. E., Babanin, A., Li, J., \& Guan, C. (2020). Spectral modeling of ice-induced wave decay. Journal of Physical Oceanography, 50(6), 1583-1604. https://doi.org/10.1175/JPO-D-19-0187.1

Meylan, M. H., Bennetts, L. G., Cavaliere, C., Alberello, A., \& Toffoli, A. (2015). Experimental and theoretical models of wave-induced flexure of a sea ice floe. Physics of Fluids, 27(4), 041704. https://doi.org/10.1063/1.4916573

Meylan, M. H., Bennetts, L. G., \& Kohout, A. L. (2014). In situ measurements and analysis of ocean waves in the Antarctic marginal ice zone. Geophysical Research Letters, 41(14), 5046-5051. https://doi.org/10.1002/2014GL060809

Meylan, M. H., Bennetts, L. G., Mosig, J. E. M., Rogers, W. E., Doble, M. J., \& Peter, M. A. (2018). Dispersion relations, power laws, and energy loss for waves in the marginal ice zone. Journal of Geophysical Research: Oceans, 123(5), 3322-3335. https://doi. org/10.1002/2018JC013776

Montiel, F., Squire, V. A., Doble, M., Thomson, J., \& Wadhams, P. (2018). Attenuation and directional spreading of ocean waves during a storm event in the autumn Beaufort Sea marginal ice zone. Journal of Geophysical Research: Oceans, 123(8), 5912-5932. https://doi. org/10.1029/2018JC013763

Overeem, I., Anderson, R. S., Wobus, C. W., Clow, G. D., Urban, F. E., \& Matell, N. (2011). Sea ice loss enhances wave action at the Arctic coast. Geophysical Research Letters, 38(17), L17503. https://doi.org/10.1029/2011GL048681

Parra, S. M., Sree, D. K., Wang, D., Rogers, E., Lee, J. H., Collins, C. O., et al. (2020). Experimental study on surface wave modifications by different ice covers. Cold Regions Science and Technology, 174, 103042. Retrieved from http://www.sciencedirect.com/science/article/ pii/S0165232X19302319; https://doi.org/10.1016/j.coldregions.2020.103042

Rabault, J., Sutherland, G., Gundersen, O., \& Jensen, A. (2017). Measurements of wave damping by a grease ice slick in Svalbard using offthe-shelf sensors and open-source electronics. Journal of Glaciology, 63(238), 372-381. https://doi.org/10.1017/jog.2017.1

Roach, L. A., Smith, M. M., \& Dean, S. M. (2018). Quantifying growth of pancake sea ice floes using images from drifting buoys. Journal of Geophysical Research: Oceans, 123(4), 2851-2866. https://doi.org/10.1002/2017JC013693

Rogers, W. E. (2019). Implementation of sea ice in the wave model SWAN (Technical Report No. 19-9874). Naval Research Laboratory.

Rogers, W. E., Posey, P., Li, L., \& Allard, R. A. (2018). Forecasting and hindcasting waves in and near the marginal ice zone: Wave modeling and the ONR "sea state" field experiment (Technical Report Nos. NRL/MR/7320-18-9786). Naval Research Laboratory. Retrieved from https://www7320.nrlssc.navy.mil/pubs.php

Rogers, W. E., Thomson, J., Shen, H. H., Doble, M. J., Wadhams, P., \& Cheng, S. (2016). Dissipation of wind waves by pancake and frazil ice in the autumn Beaufort Sea. Journal of Geophysical Research: Oceans, 121(11), 7991-8007. https://doi.org/10.1002/2016JC012251

Shen, H. H. (2019). Modelling ocean waves in ice-covered seas. Applied Ocean Research, 83, 30-36. Retrieved from http://www.sciencedirect.com/science/article/pii/S0141118718307405; https://doi.org/10.1016/j.apor.2018.12.009

Shen, H. H., \& Squire, V. A. (1998). Wave damping in compact pancake ice fields due to interactions between pancakes. Antarctic Research Series, 74, 325-341.

Squire, V. A. (2018). A fresh look at how ocean waves and sea ice interact. Philosophical Transactions of the Royal Society A: Mathematical, Physical and Engineering Sciences, 376(2129), 20170342. https://doi.org/10.1098/rsta.2017.0342

Squire, V. A., Dugan, J. P., Wadhams, P., Rottier, P. J., \& Liu, A. K. (1995). Of ocean waves and sea ice. Annual Review of Fluid Mechanics, $27,115-168$.

The WAVEWATCH III ${ }^{\circledast}$ Development Group. (2016). User manual and system documentation of WAVEWATCH III ${ }^{\circledR}$ version 5.16 (Technical Note No. 329). NOAA/NWS/NCEP/MMAB. 326 pp. + Appendices).

Thomson, J. (2012). Wave breaking dissipation observed with "SWIFT" drifters. Journal of Atmospheric and Oceanic Technology, 29(12), 1866-1882. https://doi.org/10.1175/JTECH-D-12-00018.1

Thomson, J., Ackley, S., Girard-Ardhuin, F., Ardhuin, F., Babanin, A., Boutin, G., et al. (2018). Overview of the Arctic sea state and boundary layer physics program. Journal of Geophysical Research: Oceans, 123(12), 8674-8687. https://doi.org/10.1002/2018JC013766

Thomson, J., Fan, Y., Stammerjohn, S., Stopa, J., Rogers, W. E., Girard-Ardhuin, F., et al. (2016). Emerging trends in the sea state of the Beaufort and Chukchi seas. Ocean Modelling, 105, 1-12.

Thomson, J., Gemmrich, J., Rogers, W. E., Collins, C. O., \& Ardhuin, F. (2019). Wave groups observed in pancake sea ice. Journal of Geophysical Research: Oceans, 124(11), 7400-7411. https://doi.org/10.1029/2019JC015354

Thomson, J., Hosekova, L., Meylan, M. H., Kohout, A. L., \& Kumar, N. (2020). Spurious rollover of wave attenuation rates in sea ice caused by noise in field measurements. Earth and Space Science Open Archive, 17, 11-17. https://doi.org/10.1002/essoar.10503733.1

Thomson, J., \& Rogers, W. E. (2014). Swell and sea in the emerging Arctic Ocean. Geophysical Research Letters, 41(9), 3136-3140. https:// doi.org/10.1002/2014GL059983

Ursell, F. (1953). The long-wave paradox in the theory of gravity waves. Mathematical Proceedings of the Cambridge Philosophical Society, 49(4), 685-694. https://doi.org/10.1017/S0305004100028887

Wang, X. L., Feng, Y., Swail, V. R., \& Cox, A. (2015). Historical changes in the Beaufort-Chukchi-Bering seas surface winds and waves, 1971-2013. Journal of Climate, 28(19), 7457-7469. https://doi.org/10.1175/JCLI-D-15-0190.1 